\title{
Effects of fire frequency on savanna butterfly diversity and composition: A preliminary study
}

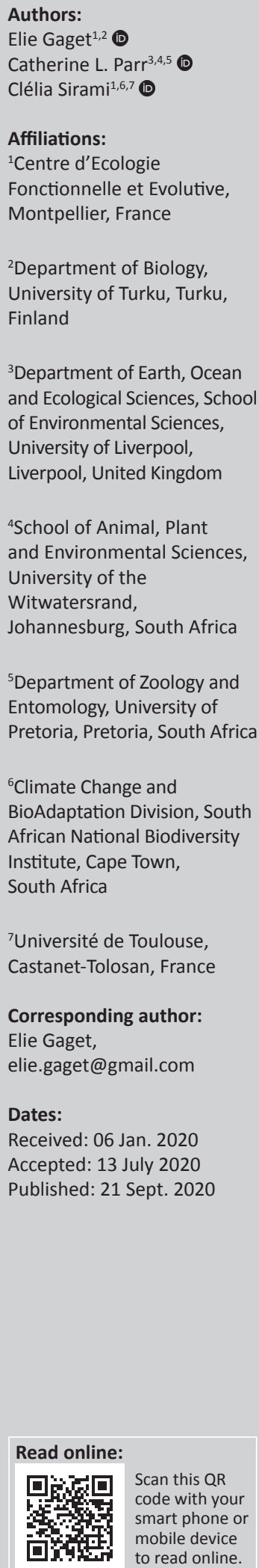

Fire plays a major role in many biomes, is widely used as a management tool and is likely to be affected by climate change. For effective conservation management, it is essential to understand how fire regimes affect different taxa, yet responses of invertebrates are particularly poorly documented. We tested how different fire frequencies influence savanna butterfly diversity and composition by using a long-term savanna fire experiment initiated in 1954 in the Kruger National Park (South Africa). We compared butterfly abundance, species richness and community composition across three fire frequencies: high (burnt annually), medium (burnt triennially) and low (burnt twice in 60 years). Plots with high fire frequency hosted higher abundance than medium- or low-frequency plots. Fire frequencies did not affect species richness, but they led to distinct communities of butterflies. Our findings suggest that, in view of the three fire frequencies tested, a spatial diversity of fire frequencies may increase butterfly diversity at the landscape level in wet savannas. Managers may need to promote a greater diversity of fire frequencies by increasing fire frequency in some areas to provide habitat for species requiring high fire frequency, and by decreasing fire frequency in a large proportion of the landscape to provide fire refuges. This study provides new insights for butterfly conservation in savannas and highlights several knowledge gaps, which further studies should address for insect responses to be given adequate consideration in fire management strategies.

Conservation implications: A spatial diversity of fire frequencies may increase butterfly diversity. Managers may need to promote a greater diversity of fire frequencies by increasing fire frequency in some areas to provide habitat for species requiring high fire frequency, and by decreasing fire frequency in other areas to provide fire refuges.

Keywords: climate change; conservation management; fire ecology; fire refugia; invertebrate pyrodiversity.

\section{Introduction}

Fire is a frequent and widespread disturbance in many biomes (Pausas \& Keeley 2009) and shapes landscapes by modifying vegetation structure and composition (Bond \& Keeley 2005). The recent increase in large uncontrolled fire incidences (e.g. in the Western-Mediterranean basin; Pausas \& Fernández-Muñoz 2012; and in the North American boreal region; Kasischke \& Turetsky 2006) and predictions indicating that the frequency of high-intensity fires will increase in the future as a result of climate change (Pechony \& Shindell 2010) have triggered growing concerns about the impacts of changes in long-term fire regimes. Fire management has become increasingly important as both human population densities and pressure to manage fuels for asset protection increase (Gill \& Stephens 2009). In parallel, fire has also become one of the primary tools for biodiversity conservation (Andersen et al. 1998; Parr \& Chown 2003). Yet, numerous knowledge gaps are still currently impeding informed decision-making in fire management (Driscoll et al. 2010).

Fire management practices for biodiversity conservation are often based on limited information, usually focussing on the response of plant communities in short-term studies or natural experiments by using space-for-time substitution (Driscoll et al. 2010). However, data on the longterm ecological response of multiple taxa to fire regimes are crucial to design appropriate fire management strategies for biodiversity conservation (Andersen et al. 1998). Despite the fact that invertebrates represent the largest component of global biodiversity and ecosystem functioning (Lavelle et al. 2006; Losey \& Vaughan 2006), they are relatively poorly studied in fire ecology research (New et al. 2010; Parr \& Chown 2003).

How to cite this article: Gaget, E., Parr, C.L. \& Sirami, C., 2020, 'Effects of fire frequency on savanna butterfly diversity and composition: A preliminary study', Koedoe 62(1), a1617. https://doi.org/10.4102/koedoe.v62i1.1617

Copyright: () 2020. The Authors. Licensee: AOSIS. This work is licensed under the Creative Commons Attribution License.

Note: Additional supporting information may be found in the online version of this article as Online Appendix 1. 
In savannas, one of the world's most fire-prone biomes, arthropods are considered to be generally well adapted to frequent fires with several recent studies across taxonomic groups highlighting their resilience (Andersen \& Müller 2000; Andersen et al. 2014; Barrow, Parr \& Kohen 2007; Davies et al. 2012; Parr et al. 2004). Most studies have observed a rapid recovery of communities after fire, between 2 and 13 months after fire, depending on the insect order and savanna type (Diniz, Higgins \& Morais 2011; Parr et al. 2004). The few existing studies on long-term savanna fire regimes observed only a weak overall effect of fire regime on insect diversity and composition, for example, for ants (Maravalhas \& Vasconcelos 2014; Parr et al. 2004) and for termites (Davies et al. 2012). Studies to date therefore suggest that little pyrodiversity (i.e. variability or diversity of fire regimes, Parr \& Andersen 2006) may be required to conserve savanna insect diversity (but see Maravalhas \& Vasconcelos 2014).

However, Beale et al. (2018) recently showed that the effects of pyrodiversity on birds and mammals across African savannas are rainfall contingent, with positive effects on these taxa particularly pronounced in wet savannas (> $650 \mathrm{~mm}$ /year). Beale et al.'s (2018) findings support studies suggesting that fire regime may have a greater effect on ants and termites in mesic savannas (> $650 \mathrm{~mm} /$ year; Davies et al. 2012; Parr et al. 2004). It therefore seems likely that invertebrates may also be more responsive to pyrodiversity in wet savannas. Furthermore, the role of fire regime may also depend on species traits, in particular specific habitat and dietary requirements. As a result, although most studies highlight the high resilience of invertebrate groups to single fire events and the weak effect of fire regime, this may not be true in wet savannas for invertebrate groups that have more specific habitat and dietary requirements.

Butterflies (Lepidoptera) are herbivorous species, commonly used as indicator species to reveal impacts of environmental change on biodiversity (e.g. Devictor et al. 2012). Butterflies might be greatly influenced by changes in vegetation structure and composition caused by changes in fire frequency (Pryke \& Samways 2012) because of their food specialisation at the larval (Gilbert \& Singer 1975) and adult (Mevi-Schütz \& Erhardt 2003) stages. Indeed, their distributions and population dynamics could be structured by the various plant species composition and structure shaped by different fire regimes (Smit et al. 2010; Smith et al. 2012). Because of their ecological requirements, butterfly species can be positively affected by frequent fires (Gardiner \& Terblanche 2010) or conversely negatively impacted by them (De Andrade et al. 2017). As a result, we expect savanna butterflies to be significantly affected by habitat differences that can develop as a result of long-term fire regimes in wetter savannas, from closed to open savanna depending of the fire frequency (Smit et al. 2010).

We studied butterfly communities associated with different fire frequencies by using a long-term fire experiment in a wet savanna (> $650 \mathrm{~mm}$ /year) of Kruger National Park, South Africa. Fire regimes can be characterised by five components (fuel consumption and spread patterns, fire intensity, severity, frequency and seasonality; Bond \& Keeley 2005), which are often correlated (Díaz-Delgado, Lloret \& Pons 2003; Govender, Trollope \& Van Wilgen 2006). We here focussed on the effect of fire frequency on butterfly communities. We sampled plots burnt at different frequencies from annual fires with open savanna to quasi-fire exclusion with closed savanna (Smit et al. 2010). Firstly, based on results observed for vertebrates (Beale et al. 2018), we expected butterfly species richness to be promoted with more frequent fires. Secondly, because changes in fire frequency induce changes in plant diversity and composition as well as vegetation structure (as already shown in the same study area by Smit et al. 2010; Smith et al. 2012), we expected fire frequency to influence both butterfly diversity and composition. Furthermore, we also expected butterfly species to show some degree of specialisation to specific fire frequencies. These last two hypotheses are related to the pyrodiversity-biodiversity hypothesis, which predicts that a spatial diversity of fire regimes should increase biodiversity at the landscape level (Parr \& Andersen 2006). Finally, because butterfly communities are likely to show dynamic patterns with time since fire, we sampled butterfly communities across three sampling periods. We expected butterfly diversity to increase with time since fire, in line with the recovery of butterfly communities, particularly in plots burnt at intermediate and high frequencies.

\section{Materials and methods Study site}

The study was conducted in the Pretoriuskop region of Kruger National Park, South Africa (KNP; 31 ${ }^{\circ} 10^{\prime} \mathrm{E}, 2^{\circ} 10^{\prime} \mathrm{S}$ ). The topography is moderately undulating, varies in altitude from 560 to $640 \mathrm{~m}$ above sea level and is dominated by nutrient-poor soils (granite-derived sandy soils). Pretoriuskop has a warm subtropical climate with annual temperature averaging $27^{\circ} \mathrm{C}$ (ranging from $4{ }^{\circ} \mathrm{C}$ to $39^{\circ} \mathrm{C}$ ) and moderately high annual rainfall $(744 \mathrm{~mm}$ /year on average; Gertenbach 1983). The wet season occurs during summer, with $85 \%$ of total annual rainfall occurring between October and March (Gertenbach 1980). The vegetation corresponds to a mesic savanna characterised by the predominance of broadleaved thornless tree species, mainly silver cluster-leaf (Terminalia sericea), marula (Sclerocarya birrea), sickle bush (Dichrostachys cinerea) and bush willow (Combretum collinum; Mucina \& Rutherford 2006). Dominant grasses include Setaria sphacelata, Digitaria eriantha and Loudetia simplex (Davies et al. 2014). Fires are typically surface fires occurring during the dry winter months with a mean return period of 3.5 years in areas that receive a mean annual rainfaXll of over $700 \mathrm{~mm}$ (Van Wilgen et al. 2000).

\section{Study design}

The experimental burn plot (EBP) trial was initiated in 1954 by using a pseudo-randomised block design (Biggs et al. 2003). Butterfly communities were sampled in three replicate sites in the Pretoriuskop area: the Numbi, Shabeni and 
Kambeni sites (Figure 1). We compared butterfly communities among three fire treatments. High fire frequency plots (hereafter referred to as high) were burnt every year in winter, and characterised by an open savanna dominated by grass species, although some tall trees were still present (Govender et al. 2006; Smith et al. 2010). Medium fire frequency plots (hereafter referred to as medium) were burnt every 3 years in winter (August 2009) and were associated with an open savanna and sparse woody vegetation (Smith et al. 2010). Low fire frequency plots (hereafter referred to as low) were subjected to less than two burn events since 1954 and were characterised by a closed savanna, dominated by woody vegetation (Smith et al. 2010). Plots associated with low fire frequency correspond to unburnt plots within the EBP where accidental fires occurred (in 2011 in Shabeni and in 2002 and 2010 in Numbi). Each plot measured approximately $380 \times 180 \mathrm{~m}$ (7 ha) and was separated from adjacent plots by firebreaks and roads. Wild megafauna was free to browse and graze on all plots. Browsing and grazing are known to interact with fire frequency (Archibald et al. 2005). The present study does not aim to disentangle the respective effect of fire frequency and browsing or grazing, a topic already investigated in other studies (see Burkepile et al. 2016; Trollope et al. 2014). We studied the three fire treatments at each of the three sites, that is a total of nine plots; replication was limited because of experimental design constraints, but the uniqueness of this fire experiment specifically its long-term and large-scale nature - makes the results valuable (see also Parr et al. 2004).

\section{Butterfly sampling}

Butterfly communities were surveyed in each plot by using the Pollard walk transect method commonly used in the literature (Pollard \& Yates 1993). Surveys were conducted by

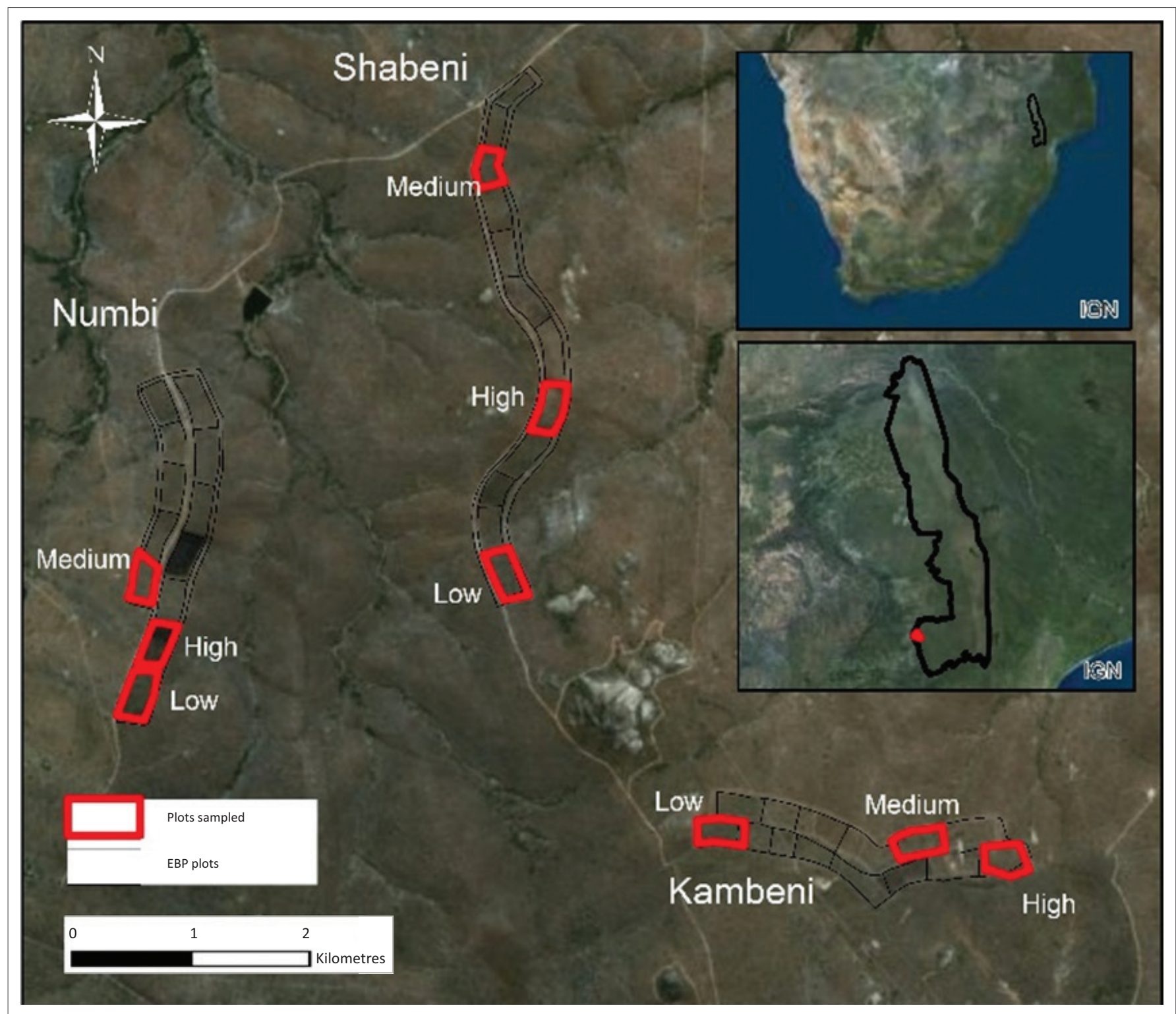

Source: Esri, DigitalGlobe, GeoEye, Earthstar Geographics, CNES/Airbus DS, USDA, USGS, AeroGRID, IGN, and the GIS user community EBP, experimental burn plot.

FIGURE 1: The pretoriuskop study area in the south-western part of the Kruger National Park (lower insert, $31^{\circ} 10^{\prime} \mathrm{E}, 25^{\circ} 10^{\prime} \mathrm{S}$ ), South Africa (upper insert). Black rectangles correspond to the long-term experimental burn plots set up in 1954 and red rectangles represent the nine plots sampled within the three sites (Numbi, Shabeni and Kambeni). 
a team of local butterfly experts led by I.A. Sharp during the austral summer (December-March), which corresponds to the peak flight period for most butterfly species (Woodhall 2005). Each plot was visited during three sampling periods in December 2009, March 2010 and January 2012. Consequently, in plots with medium fire frequency, sampling was conducted 4, 7 and 29 months after burning, whereas high-frequency plots were sampled at 4,5 and 7 months after burning. During each sampling period, two transects of $380 \mathrm{~m}$ were sampled between opposite corners of the plot (transects started $20 \mathrm{~m}$ away from the border of the plot to limit edge effects). For each sampling period, we considered species richness and abundance per plot as the total number of species and the total number of individuals recorded on the two transects, respectively. Butterflies were recorded by walking along each transect at a steady pace (around $12 \mathrm{~m} /$ $\mathrm{min}$ ), thus taking $30 \mathrm{~min}$ to be completed. Our sampling effort was therefore similar to those commonly used in the literature and can be considered sufficient to compare species diversity and composition between plots (e.g. Davis, Debinski \& Danielson 2007; Koh \& Sodhi 2004; Vasconcelos et al. 2015). In our study, we observed 78 species (see below), which corresponds to $72 \%$ of the 108 species occurring in our study area (Pretoriuskop; based on Otto 2014). Considering that our sampling sites only include open-closed savanna (Smit et al. 2010), but not other habitats found in this area, this suggests that our sampling provides a good representation of the local butterfly community (Online Appendix 1 Figure S2). Nevertheless, we acknowledge that sampling in December, January and March resulted in the exclusion of at least 15 species observed only during the rest of the year, based on the Atlas of African Lepidoptera (FitzPatrick Institute of African Ornithology 2020). Surveys were restricted to clear, windless days between 10:00 and 14:00. All butterflies seen within $5 \mathrm{~m}$ of the transect line were recorded (Pollard 1977). Most butterflies were identified to species level; when this was not possible, the recorder would net the butterfly and identify the species in the field. Individuals flying from behind the recorders were excluded to avoid double counting (Pollard 1977).

\section{Statistical analyses}

To evaluate differences in species richness and abundance across the different fire frequencies, the cumulative species richness and abundance over the three sampling periods was calculated. A generalised linear mixed-effects model (GLMM, Poisson error distribution) was applied to data with species richness and abundance set as response variables and fire frequency (i.e. high, medium and low) set as explanatory variables. Site identity (Numbi, Shabeni and Kambeni) was added as random factor (see Online Appendix 1 Figure S1 for the effect of site identity on cumulative species richness and cumulative abundance). The likelihood-ratio chi-square was computed to interpret the significance of each model, and data were checked for residual homoscedasticity.

Differences in community composition between the three fire frequencies, based on cumulative presence or absence and abundance data over the three sampling periods, were evaluated by using the Jaccard dissimilarity on butterfly species presence or absence and Bray-Curtis dissimilarity on abundance. Both these indices exclude joint absences and do not consider double absences as a factor of similarity (Legendre \& Legendre 1998). A principal coordinates analysis (PCoA, package 'ade4', Dray \& Dufour 2007) was constructed to visually represent differences in community composition between the three fire frequencies based on Jaccard (presence or absence) and Bray-Curtis (abundance) distance matrices. Principal coordinates analysis is used to represent objects from a distance matrix by preserving the distance relationships among objects in the full-dimensional principal coordinate Euclidean space (Gower 1966). We also performed a permutational multivariate analysis of variance (PERMANOVA, function 'adonis' in package 'vegan', Oksanen et al. 2013) on the Jaccard and Bray-Curtis distance matrix with fire frequency as an explanatory variable.

Additionally, we conducted an indicator species analysis (IndVal; Dufrêne \& Legendre 1997) to determine whether certain butterfly associated more strongly with particular fire frequencies. IndVal was applied to identify species associations with fire frequencies for each sampling period. We used the function 'multipatt' (package 'indicspecies', De Caceres \& Jansen 2016). Based on McGeoch, Van Rensburg and Botes (2002), we retained only indicator species with significant IndVals greater than $70 \%$.

The recovery of butterfly diversity with time since fire in plots burnt at high and medium fire frequencies was determined by analysing the effect of time since fire on species richness and abundance for these two fire frequencies. To this end, a GLMM (Poisson error distribution, package 'Ime4', Bates et al. 2014) was applied for each fire frequency (high and medium), with species richness and abundance as a response variable and sampling period as an explanatory variable (December 2009, March 2010, January 2012). Site identity (Numbi, Shabeni and Kambeni) was added as a random factor. The likelihood-ratio chi-square was computed to interpret the significance of each model, and we checked for residual homoscedasticity.

All statistical analyses and graphic representations were conducted in R 3.4.3 (R Development Core Team 2018).

\section{Ethical consideration}

This article followed all ethical standards for a research without direct contact with human or animal subjects.

\section{Results}

A total of 1809 individuals from 78 species were recorded, with an average of $67 \pm 53.3$ individuals (mean \pm standard deviation) and $14.8 \pm 4.9$ species per plot per sampling period. Twelve of these species were recorded in more than 10 sampling periods, although 39 species (50\% of all species) were recorded in three or less of the sampling periods (Online Appendix 1). 


\section{Effect of fire frequency on butterfly species richness and abundance}

Species richness did not differ significantly between the three fire frequencies (Figure 2, $X^{2}=0.65$, degree of freedom $[d f]=5$, $p=0.7)$. However, butterfly abundance was significantly higher in high-frequency plots, compared with the medium (Figure 2, $\beta=0.53 \pm 0.06, d f=2, z=9.21, p<0.001$ ) and low fire frequency plots (Figure 2, $\beta=0.52 \pm 0.06, d f=2, z=9.06$, $p<0.001)$. Abundance did not differ significantly between medium and low fire frequency plots (Figure 2, $p>0.05$ ). The random effect associated with site identity was not highly informative in the applied model (deviance $<0.0001$ ). However, abundance varied significantly between sites, whereas species richness did not reveal any significant variation between sites (Online Appendix 1 Figure S1).

\section{Effect of fire frequency on community composition}

The first two axes of the analysis based on the presence or absence data (Jaccard) explained $40.6 \%$ and $20.4 \%$ of the inertia (Figure 3a), whereas the first two axes based on abundance data (Bray-Curtis) explained 20.9\% and 20.5\% of the inertia (Figure 3b). Community composition based on abundance data (Bray-Curtis) was significantly affected by fire frequency $\left(F=2.45, r^{2}=0.43, p=0.006\right)$. Community composition based on the presence or absence was not significantly different between fire frequencies, despite a low $p$-value $\left(F=1.54, r^{2}=0.34, p=0.07\right)$. Both analyses revealed a heavily structured distribution of plots burnt at different frequencies along the first axis (Figure $3 a$ and $b$ ).

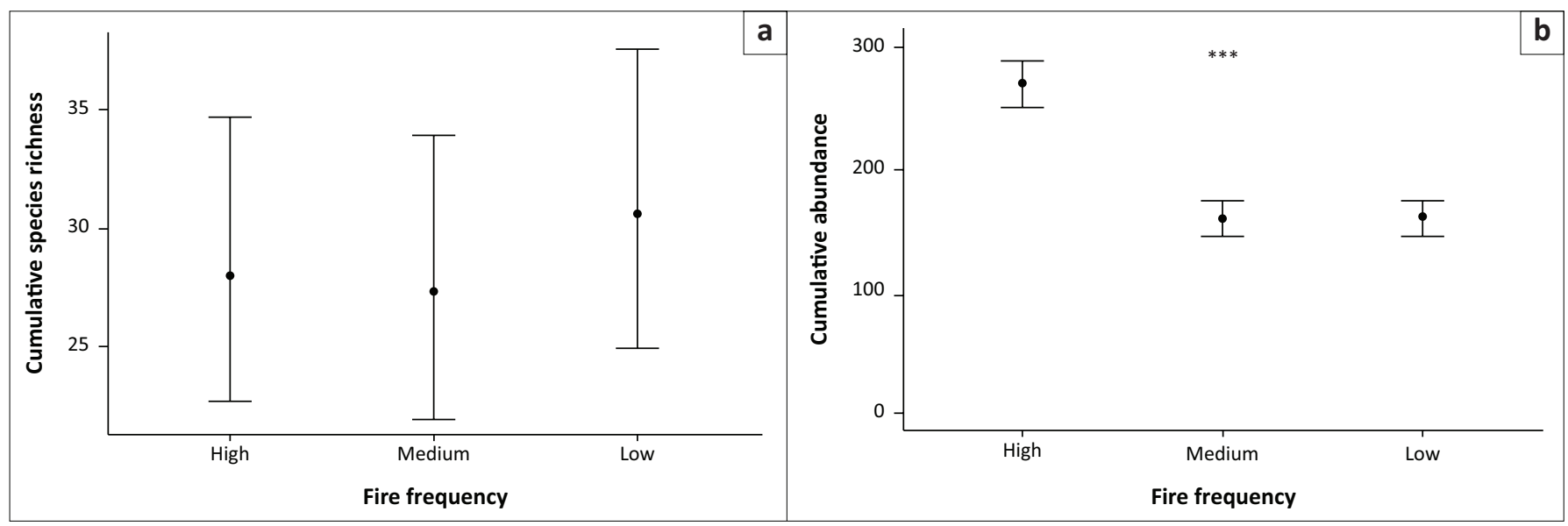

FIGURE 2: The effect of fire frequency on cumulative species richness (a) and cumulative abundance (b) over the three sampling periods. Overall significant differences $(95 \%$ confidence interval) are indicated by $* * *(p<0.001)$. Fire frequencies associated with distinct letters are significantly different.

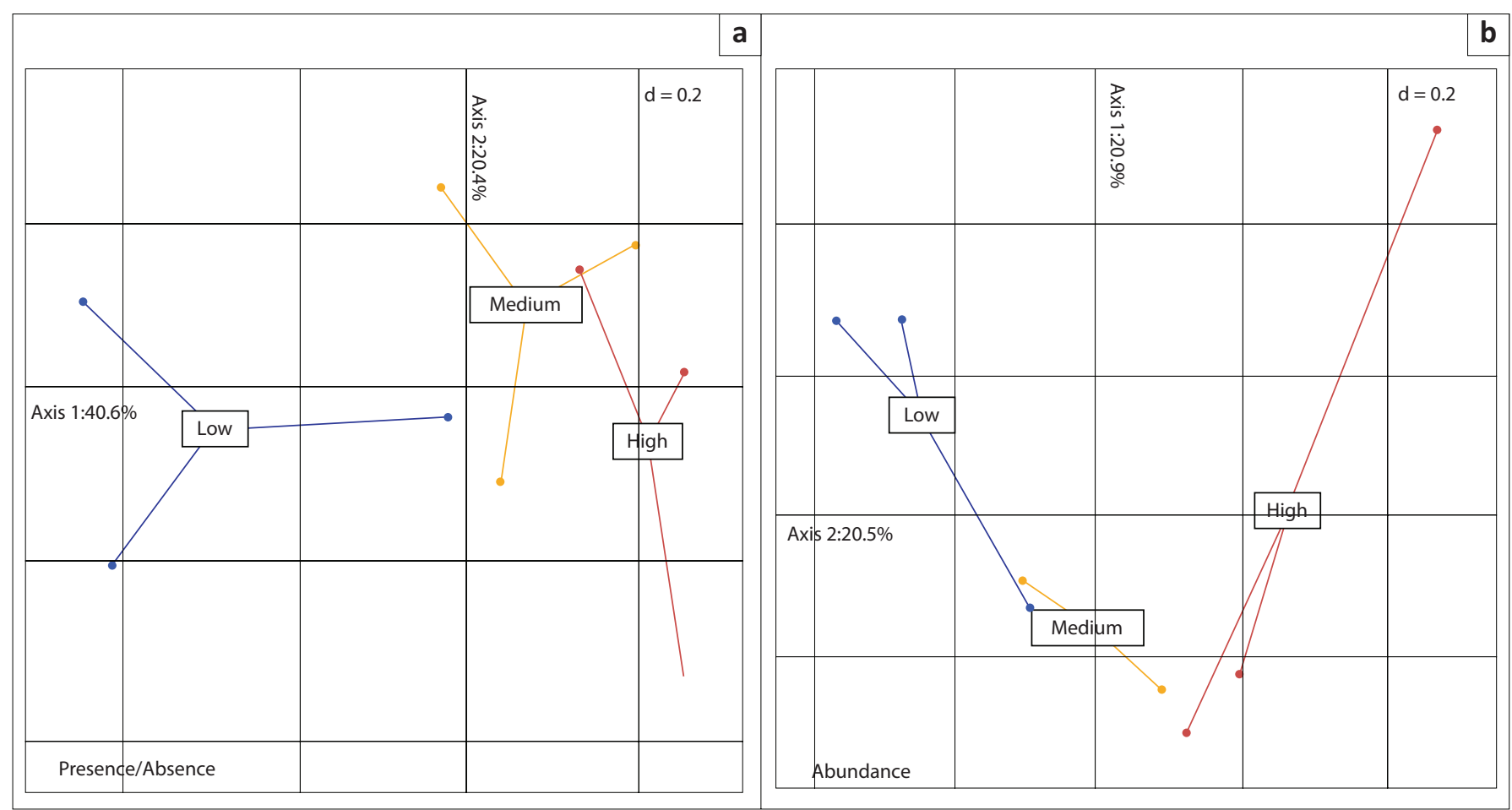

FIGURE 3: Position of fire frequencies on the axes 1-2 of the principal coordinates analysis performed on the distance matrix of the presence or absence (a, Jaccard) the abundance (b, Bray-Curtis). 


\section{Indicator species}

Five species were strongly associated with a specific fire frequency (Table 1; see abundance per fire frequency, per period and per site for these five species in Table 2). Among these species, cupreous blue (Eicochrysops messapus) and broad-bordered grass yellow (Eurema brigitta brigitta) were indicators of most frequently burnt plots (high and medium), whilst common blue (Leptotes pirithous pirithous), clearspotted acraea (Acraea aglaonice) and Zulu shadefly (Coenyra hebe) were indicators of infrequently burnt plots (low) (Online Appendix 1 Figure S3).

\section{Recovery of butterfly diversity after fire}

In plots burnt at high fire frequency, species richness did not differ significantly between 4,5 and 7 months after fire (Figure $4, X^{2}=2.15, p=0.3$ ). However, abundance was significantly higher 5 months after fire, compared with 4 and 7 months after fire $(\beta=1.43 \pm 0.10, z=14.83, p<0.001$ and $\beta=1.40 \pm 0.10, z=14.70, p<0.001$, respectively). Abundance did not differ between 4 and 7 months after fire $(\beta=0.30 \pm 0.10$,

TABLE 1: Percentage of species association with each fire frequency (high, medium and low) during each sampling period (December, January and March) and associated $p$-value based on the IndVal analysis.

\begin{tabular}{lllcc}
\hline Period & Fire frequency & Species & $\mathbf{\%}$ & $\boldsymbol{p}$ \\
\hline December & High & - & - & - \\
& Medium & - & - & - \\
& Low & Common blue & 82.2 & 0.03 \\
\multirow{2}{*}{ January } & High & Cupreous blue & 97.0 & 0.045 \\
& Medium & - & - & - \\
& Low & Clear-spotted Acraea & 91.8 & 0.035 \\
\multirow{3}{*}{ March } & High & - & - & - \\
& Medium & Broad-bordered grass yellow & 84.6 & 0.042 \\
& Low & Common blue & 82.2 & 0.032 \\
& & Zulu shadefly & 91.4 & 0.032 \\
\hline
\end{tabular}

TABLE 2: Abundance of each identified indicator species per fire frequency, per sampling period and per site.

\begin{tabular}{|c|c|c|c|c|c|c|c|}
\hline Species & $\begin{array}{l}\text { Species } \\
\text { association }\end{array}$ & $\begin{array}{l}\text { Fire } \\
\text { frequency }\end{array}$ & Kambeni & Numbi & Shabeni & Total & Period \\
\hline \multirow{3}{*}{$\begin{array}{l}\text { Cupreous } \\
\text { blue }\end{array}$} & \multirow[t]{3}{*}{ High } & High & 1 & 7 & 1 & 9 & \multirow[t]{6}{*}{ December } \\
\hline & & Medium & 0 & 0 & 0 & 0 & \\
\hline & & Low & 0 & 0 & 0 & 0 & \\
\hline \multirow{3}{*}{$\begin{array}{l}\text { Common } \\
\text { blue }\end{array}$} & \multirow[t]{3}{*}{ Low } & High & 0 & 0 & 0 & 0 & \\
\hline & & Medium & 0 & 0 & 0 & 0 & \\
\hline & & Low & 3 & 1 & 1 & 5 & \\
\hline \multirow{3}{*}{$\begin{array}{l}\text { Cupreous } \\
\text { blue }\end{array}$} & \multirow[t]{3}{*}{ High } & High & 20 & 32 & 29 & 81 & \multirow[t]{6}{*}{ January } \\
\hline & & Medium & 0 & 3 & 1 & 4 & \\
\hline & & Low & 0 & 0 & 2 & 2 & \\
\hline \multirow{3}{*}{$\begin{array}{l}\text { Clear- } \\
\text { spotted } \\
\text { Acraea }\end{array}$} & \multirow[t]{3}{*}{ Low } & High & 0 & 0 & 0 & 0 & \\
\hline & & Medium & 0 & 0 & 0 & 0 & \\
\hline & & Low & 1 & 2 & 1 & 4 & \\
\hline \multirow{3}{*}{$\begin{array}{l}\text { Broad- } \\
\text { bordered } \\
\text { grass } \\
\text { yellow }\end{array}$} & \multirow[t]{3}{*}{ Medium } & High & 7 & 12 & 20 & 39 & \multirow[t]{3}{*}{ March } \\
\hline & & Medium & 24 & 25 & 35 & 84 & \\
\hline & & Low & 1 & 3 & 5 & 9 & \\
\hline \multirow{3}{*}{$\begin{array}{l}\text { Common } \\
\text { blue }\end{array}$} & \multirow[t]{3}{*}{ Low } & High & 1 & 0 & 0 & 1 & \\
\hline & & Medium & 0 & 0 & 0 & 0 & \\
\hline & & Low & 13 & 4 & 2 & 19 & \\
\hline \multirow{3}{*}{$\begin{array}{l}\text { Zulu } \\
\text { shadefly }\end{array}$} & \multirow[t]{3}{*}{ Low } & High & 0 & 0 & 0 & 0 & \\
\hline & & Medium & 0 & 0 & 0 & 0 & \\
\hline & & Low & 6 & 3 & 8 & 17 & \\
\hline
\end{tabular}

$z=0.24, p=0.9)$. The random effect associated with site identity was not highly informative in each model (deviance $<0.0001$ ).

In plots burnt at medium fire frequency, butterfly species richness and abundance were significantly affected by time since fire (Figure 4, $X^{2}=10.39, p=0.006 ; X^{2}=60.04, p<0.001$, respectively). Species richness was lower 4 months after burning than 7 and 29 months after burning (Figure 4, $\beta=-0.56 \pm 0.26, z=-2.19, p=0.03 ; \beta=-0.79 \pm 0.25, z=-3.22$, $p=0.001$, respectively). Similarly, abundance was lower 4 months after burning than 7 and 29 months after burning (Figure 4, $\beta=-0.89 \pm 0.13, z=-6.69, p<0.001 ; \beta=-0.99 \pm 0.13$, $z=-7.53, p<0.001$, respectively). However, neither the species richness nor the abundance differs between 7 and 29 months after fire (Figure $4, \beta=0.23 \pm 0.21, z=1.13$, $p=0.2 ; \beta=0.10 \pm 0.10, z=0.99, p=0.3$, respectively). The random effect associated with site identity was not highly informative in each model (deviance $<0.0001$ ).

\section{Discussion}

This study represents a first assessment on the effect of differences in long-term fire frequencies on butterfly communities in wet African savannas. We observed significant differences in species abundance and species composition between fire frequencies.

The high abundance of butterflies observed in high fire frequency plots lends support to the idea that most savanna butterfly species are resilient to, or favoured by, some level of disturbance compared with no disturbance (Wilkerson, Roche \& Young 2013). Butterflies are sensitive to changes in plant diversity, which may influence their distribution at both larval and adult stage (Gilbert \& Singer 1975; MeviSchütz \& Erhardt 2003). The fact that herbaceous species diversity is greater in plots burnt at high frequency than in plots burnt at medium frequency in the Kruger National Park (Burkepile et al. 2016) may contribute to increased butterfly species abundances.

The results partially confirm the specialisation hypothesis that predicts that different fire frequencies hosting different plant species composition will be associated with different butterfly communities (Gilbert \& Singer 1975). Significant differences across fire frequencies (Figures $3 a$ and $b$ ) is in accord with the fact that differences in fire frequency result in differences in plant species composition, as already shown in the same study area (Smith et al. 2012). In this long-term experiment, herbaceous vegetation has been shown to be heavily influenced by fire frequency, with lower herbaceous diversity in plots burnt at low frequency than in plots burnt at high or medium frequencies (Smith et al. 2012). This was true even it is accidental fire occurred in the low fire frequency plots, where the differences in vegetation structure and composition compared with frequently burnt plots remain very high. Such differences in host plants for the larval stage or flowers for the adult stage are likely to explain differences in butterfly community composition observed 


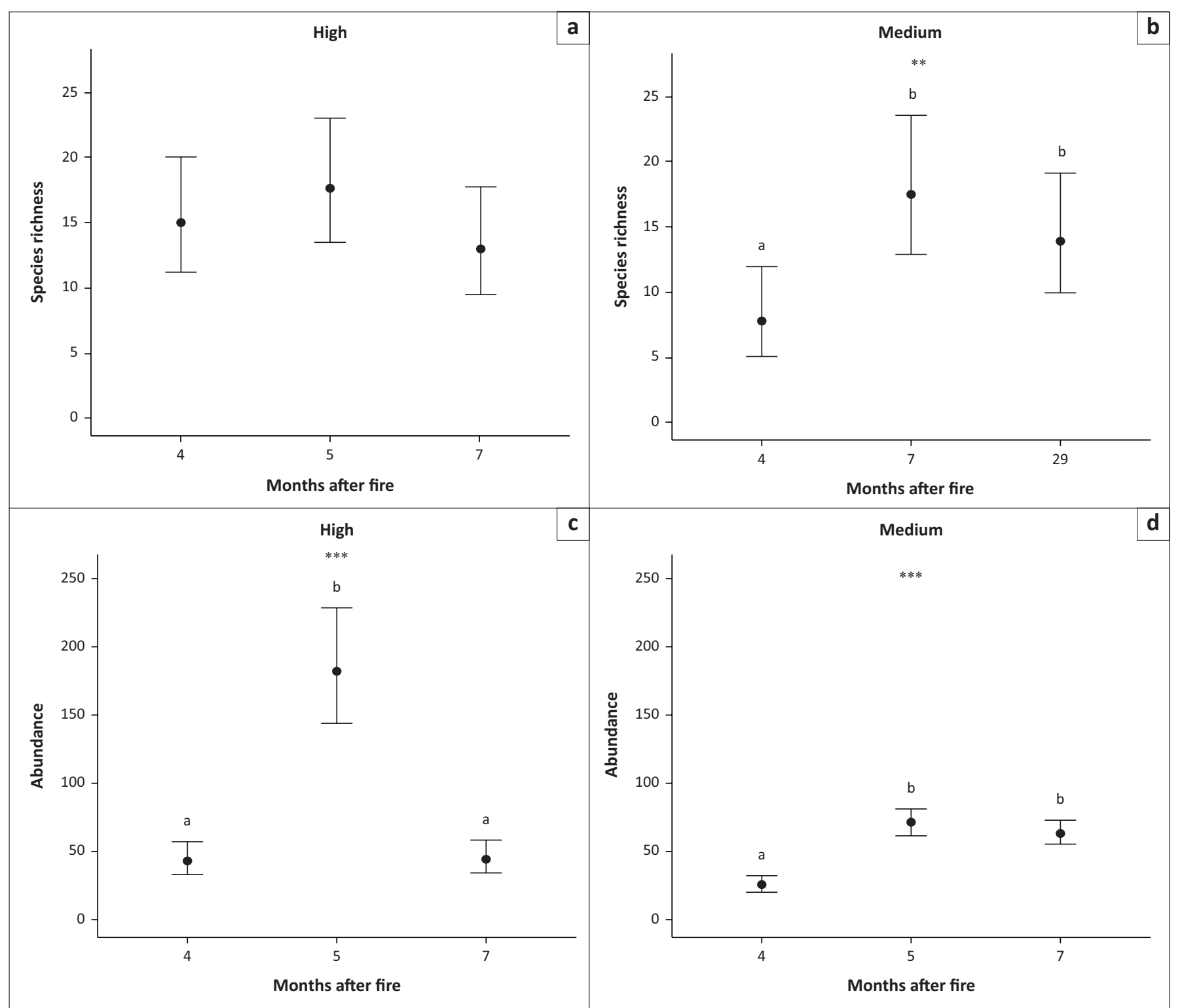

FIGURE 4: Effect of time since fire on butterfly species richness and abundance for high fire frequency (annual burning in August) and medium fire frequency (triennial burning in August). Overall significant differences ( $95 \%$ confidence interval) are indicated by $* *(p<0.01)$ or $* * *(p<0.001)$. Significant time effects on the species richness and abundance are indicated by lowercase letters.

among EBPs (Swengel 2001). Accurate monitoring of the diversity of host plants and data on butterfly functional traits would, however, be necessary to confirm this preliminary finding.

We identified indicator species for each fire frequency, suggesting that butterfly species respond differently to variations in fire frequency. Literature suggests that butterfly forest specialists are generally sensitive to fire and can be negatively affected by frequent burning (De Andrade et al. 2017). Accordingly, we found that low fire frequency benefits the species that prefer shaded areas in mixed woodland and forest, like the Zulu shadefly (Online Appendix 1 Figure S3). Conversely, medium and high fire frequencies had positive effects on some open savanna species, such as the broadbordered grass yellow and the cupreous blue (Online Appendix 1 Figure S3), which are resilient to fire and promoted by frequent burning (Adamidis et al. 2019).
This study furthermore suggests that butterfly diversity may be able to recover quickly after a fire. Indeed, butterfly species richness and abundance were similar 7 months and 29 months after the last fire in plots burnt triennially. This high speed of recovery has also been observed with ants (Parr et al. 2004) - likely linked to rapid recovery of vegetation. The recovery of butterfly communities could be attributed to an immigration effect from the surrounding landscape (Moranz, Fuhlendorf \& Engle 2014; Robinson et al. 2013). The small size of experimental plots means that recovery time may be longer in natural landscapes where bigger fires occur. Further research is necessary to address variations in recovery time between species (Vogel, Koford \& Debinski 2010).

This study was conducted in one of the largest and oldest fire experiments globally. Despite its many advantages, it is important to acknowledge the limitations with this long-term experiment, especially for mobile invertebrates such as 
butterflies. In their adult stage, butterflies can cover vast distances (hundreds of metres) (Pollard 1977) and are therefore able to move from one 7 ha plot to another. Although we did not include individual butterflies along the border of plots $(20 \mathrm{~m})$, it is possible that some of the individuals recorded during our surveys came from outside the plots. The presence of non-local vagrant butterflies may have influenced our ability to accurately assess species diversity (Avuletey \& Niba 2014). This may explain the lack of difference in community composition based on species occurrence between fire frequencies in our study. More research should be conducted on transient individuals, notably on their ability to cross different vegetation structures, to assess differences in community composition and species richness between EBPs with higher certainty levels (Wood \& Samways 1991). Additionally, even long-term experiment may be affected by inter-annual variations, such as, for instance, different climatic variations between years impacting either fire intensity or vegetation recovery after fire. For example, some species were very abundant 5 months after fire compared with 4 or 7 months after fire, in the high frequently burnt plot (Figure 2). Indeed, 4 and 7 months after fire correspond to the summer 2009-2010, although 5 months after fire correspond to 2012. Lastly, although we appreciate the sample size is relatively low, the size and duration of this experiment are valuable. Moreover, nevertheless, we were able to detect differences among the treatments suggesting that in this habitat, fire regimes can have a significant impact on butterfly communities.

This preliminary assessment focusses on fire frequency, an easy parameter for conservation managers to measure (Biggs et al. 2003). In the Pretoriuskop area of Kruger National Park, no part of the landscape currently has a fire return period of 2 years or less (SANPARKS, unpublished) and only $6 \%$ of the area burns infrequently (fire return period of $>5$ years; SANPARKS, unpublished). This suggests that managers may need to promote a greater diversity of fire frequencies by (1) increasing fire frequency in some areas to provide habitat for species requiring high fire frequency; and (2) decreasing fire frequency in a larger proportion of the area. Our study highlights that insect responses should be given more consideration to determine whether the current fire strategy in Kruger National Park is adequate in the long term for biodiversity conservation. Further studies should be conducted to explore the role of other components of fire regime on wet savanna biodiversity (Beale et al. 2018; Hempson et al. 2017) in relation with butterfly dispersal capacities and the ability of larvae to escape fire, to explicitly address colonisation and extinction processes after fire.

\section{Acknowledgements}

We are especially grateful to Ian and Allison Sharp and their family for conducting all the butterfly surveys as well as all the volunteers who assisted them, in particular Valentina Lupano, Richard Mercer and Julie Wolhunter. We thank South African National Parks, and especially Navashni Govender, for logistical support. We gratefully acknowledge funding from the Rufford Small Grants, National Geographic and Oxford University John Fell Fund. We thank the two anonymous reviewers for helpful comments.

\section{Competing interests}

The authors have declared that no competing interest exists.

\section{Authors' contributions}

E.G., C.S. and C.L.P. conceived and designed the study, E.G. and C.S. performed the analyses, E.G. and C.S. wrote the manuscript and all authors edited and approved it.

\section{Funding information}

Funding for the study was received from the Rufford Small Grants, National Geographic and Oxford University John Fell Fund.

\section{Data availability statement}

The data used in this study will be archived in the Dryad Digital Repository.

\section{Disclaimer}

The views and opinions expressed in this article are those of the authors and do not necessarily reflect the official policy or position of any affiliated agency of the authors.

\section{References}

Adamidis, G.C., Swartz, M.T., Zografou, K. \& Sewall, B.J., 2019, 'Prescribed fire maintains host plants of a rare grassland butterfly', Scientific Reports 9(1), 1-12. https://doi.org/10.1038/s41598-019-53400-1

Andersen, A.N., Braithwaite, R.W., Cook, G.D., Corbett, L.K., Williams, R.J., Douglas, M.M. et al., 1998, 'Fire research for conservation management in tropical savannas: Introducing the Kapalga fire experiment', Australian Journal of Ecology 23(2), 95-110. https://doi.org/10.1111/j.1442-9993.1998.tb00708.x

Andersen, A.N. \& Müller, W.J., 2000, 'Arthropod responses to experimental fire regimes in an Australian tropical savannah: Ordinal-level analysis', Austral Ecology 25(2), 199-209. https://doi.org/10.1046/j.1442-9993.2000.01038.x

Andersen, A.N., Ribbons, R.R., Pettit, M. \& Parr, C.L., 2014, 'Burning for biodiversity: Highly resilient ant communities respond only to strongly contrasting fire regimes in Australia's seasonal tropics', Journal of Applied Ecology 51(5), 1406-1413. https://doi.org/10.1111/1365-2664.12307

Archibald, S., Bond, W.J., Stock, W.D. \& Fairbanks, D.H.K., 2005, 'Shaping the landscape: Fire-grazer interactions in an African savanna', Ecological Applications 15(1), 96-109. https://doi.org/10.1890/03-5210

Avuletey, R. \& Niba, A.S., 2014, 'Butterfly (Lepidoptera) assemblage composition and distribution patterns in King Sabata Dalindyebo Municipality, Eastern Cape, South Africa', African Entomology 22(1), 57-67. https://doi.org/10.4001/003.022.0103

Barrow, L., Parr, C.L. \& Kohen, J.L., 2007, 'Habitat type influences fire resilience of ant assemblages in the semi-arid tropics of Northern Australia', Journal of Arid Environments 69(1), 80-95. https://doi.org/10.1016/j.jaridenv.2006.08.005

Bates, D., Maechler, M., Bolker, B. \& Walker, S., 2014, 'Ime4: Linear mixed-effects models using eigen and S4', $R$ Package Version 1(7), 1-23. https://doi. org/10.18637/jss.v067.i01

Beale, C.M., Courtney Mustaphi, C.J., Morrison, T.A., Archibald, S., Anderson, T.M. Dobson, A.P. et al., 2018, 'Pyrodiversity interacts with rainfall to increase bird and mammal richness in African savannas', Ecology Letters 21(4), 557-567. https:// doi.org/10.1111/ele.12921

Biggs, R., Biggs, H.C., Dunne, T.T., Govender, N. \& Potgieter, A.L.F., 2003, 'Experimental burn plot trial in the Kruger National Park: History, experimental design and suggestions for data analysis', Koedoe - African Protected Area Conservation and Science 46(1), 1-15. https://doi.org/10.4102/koedoe.v46i1.35

Bond, W.J. \& Keeley, J.E., 2005, 'Fire as a global "herbivore": The ecology and evolution of flammable ecosystems', Trends in Ecology \& Evolution 20(7), 387-394. https:// doi.org/10.1016/j.tree.2005.04.025

Burkepile, D.E., Thompson, D.I., Fynn, R.W.S., Koerner, S.E., Eby, S., Govender, N. et al . 2016, 'Fire frequency drives habitat selection by a diverse herbivore guild impacting top-down control of plant communities in an African savanna', Oikos 125(11), 1636-1646. https://doi.org/10.1111/oik.02987 
Davies, A.B., Eggleton, P., Van Rensburg, B.J. \& Parr, C.L., 2012, 'The pyrodiversitybiodiversity hypothesis: A test with savanna termite assemblages', Journal of AppliedEcology49(2),422-430. https://doi.org/10.1111/j.1365-2664.2012.02107.x

Davies, A.B., Robertson, M.P., Levick, S.R., Asner, G.P., Van Rensburg, B.J. \& Parr, C.L., 2014, 'Variable effects of termite mounds on African savanna grass communities across a rainfall gradient', Journal of Vegetation Science 25(6), 1405-1416. https://doi.org/10.1111/jvs.12200

Davis, J.D., Debinski, D.M. \& Danielson, B.J., 2007, 'Local and landscape effects on the butterfly community in fragmented Midwest USA prairie habitats', Landscape Ecology 22(9), 1341-1354. https://doi.org/10.1007/s10980-007-9111-9

De Andrade, R.B., Balch, J.K., Carreira, J.Y., Brando, P.M. \& Freitas, A.V., 2017, 'The impacts of recurrent fires on diversity of fruit-feeding butterflies in a southeastern Amazon forest', Journal of Tropical Ecology 33(1), 22. https://doi. org/10.1017/S0266467416000559

De Caceres, M. \& Jansen, F., 2016, 'Package “indicspecies"', Indicators 8, 1.

Devictor, V., Van Swaay, C., Brereton, T., Brotons, L., Chamberlain, D., Heliölä, J. et al., 2012, 'Differences in the climatic debts of birds and butterflies at a continenta scale', Nature Climate Change 2(2), 121-124. https://doi.org/10.1038/nclimate1347

Díaz-Delgado, R., Lloret, F. \& Pons, X., 2003, 'Influence of fire severity on plant regeneration by means of remote sensing imagery', International Journal of

Diniz, I.R., Higgins, B. \& Morais, H.C., 2011, 'How do frequent fires in the Cerrado alter the lepidopteran community?', Biodiversity and Conservation 20(7), 1415-1426. https://doi.org/10.1007/s10531-011-0034-z

Dray, S. \& Dufour, A.B., 2007, 'The ade4 package: Implementing the duality diagram for ecologists', Journal of Statistical Software 22(4), 1-20. https://doi.org/ 10.18637/jss.v022.i04

Driscoll, D.A., Lindenmayer, D.B., Bennett, A.F., Bode, M., Bradstock, R.A., Cary, G.J. et al., 2010, 'Fire management for biodiversity conservation: Key research questions and our capacity to answer them', Biological Conservation 143(9), 1928-1939. and our capacity to answer them', Biological
https://doi.org/10.1016/j.biocon.2010.05.026

Dufrêne, M. \& Legendre, P., 1997, 'Species assemblages and indicator species: The need for a flexible asymmetrical approach', Ecological Monographs 67(3), 345-366. https://doi.org/10.2307/2963459

FitzPatrick Institute of African Ornithology, 2020, LepiMAP: Atlas of African Lepidoptera, viewed 24 June 2020, from http://vmus.adu.org.za/?vm=LepiMAP.

Gardiner, A.J. \& Terblanche, R.F., 2010, 'Taxonomy, biology, biogeography, evolution and conservation of the genus Erikssonia Trimen (Lepidoptera: Lycaenidae)', African Entomology 18(1), 171-191. https://doi.org/10.4001/003.018.0114

Gertenbach, W.P.D., 1980, 'Rainfall patterns in the Kruger National Park', Koedoe African Protected Area Conservation and Science 23(1), 35-43. https://doi. org/10.4102/koedoe.v23i1.634

Gertenbach, W.P.D., 1983, 'Landscapes of the Kruger National Park', Koedoe - African Protected Area Conservation and Science 26(1), 9-121. https://doi.org/10.4102/ koedoe.v26i1.591

Gilbert, L.E. \& Singer, M.C., 1975, 'Butterfly ecology', Annual Review of Ecology and Systematics6(1),365-395.https://doi.org/10.1146/annurev.es.06.110175.002053

Gill, A.M. \& Stephens, S.L., 2009, 'Scientific and social challenges for the management of fire-prone wildland-urban interfaces', Environmental Research Letters 4(3) 034014. https://doi.org/10.1088/1748-9326/4/3/034014

Govender, N., Trollope, W.S. \& Van Wilgen, B.W., 2006, 'The effect of fire season, fire frequency, rainfall and management on fire intensity in savanna vegetation in South Africa', Journal of Applied Ecology 43(4), 748-758. https://doi.org/10.1111/ j.1365-2664.2006.01184.x

Gower, J.C., 1966, 'Some distance properties of latent root and vector methods used in multivariate analysis', Biometrika 53(3-4), 325-338. https://doi.org/10.1093/ biomet/53.3-4.325

Hempson, G.P., Parr, C.L., Archibald, S., Anderson, T.M., Mustaphi, C.J.C., Dobson, A.P. et al., 2017, 'Continent-level drivers of African pyrodiversity', Ecography 41(6), 889-899. https://doi.org/10.1111/ecog.03109

Kasischke, E.S. \& Turetsky, M.R., 2006, 'Recent changes in the fire regime across the North American boreal region - Spatial and temporal patterns of burning across Canada and Alaska', Geophysical Research Letters 33(9), 1-5. https://doi. org/10.1029/2006GL025677

Koh, L.P. \& Sodhi, N.S., 2004, 'Importance of reserves, fragments, and parks for butterfly conservation in a tropical urban landscape', Ecological Application 14(6), 1695-1708. https://doi.org/10.1890/03-5269

Lavelle, P., Decaëns, T., Aubert, M., Barot, S., Blouin, M., Bureau, F. et al., 2006, 'Soil invertebrates and ecosystem services', European Journal of Soil Biology 42(Suppl 1), S3-S15. https://doi.org/10.1016/j.ejsobi.2006.10.002

Legendre, P. \& Legendre, L., 1998, Numerical ecology, Volume 24, (Developments in environmental modelling), Elsevier, Québec.

Losey, J.E. \& Vaughan, M., 2006, 'The economic value of ecological services provided by insects', BioScience 56(4), 311-323. https://doi.org/10.1641/0006-3568(2006) 56[311:TEVOES]2.0.CO;2

Maravalhas, J. \& Vasconcelos, H.L., 2014, 'Revisiting the pyrodiversity-biodiversity hypothesis: Long-term fire regimes and the structure of ant communities in Neotropical savanna hotspot', Journal of Applied Ecology 51(6), 1661-1668. https://doi.org/10.1111/1365-2664.12338

Mcgeoch, M.A., Van Rensburg, B.J. \& Botes, A., 2002, 'The verification and application of bioindicators: A case study of dung beetles in a savanna ecosystem', Journal of AppliedEcology39(4),661-672.https://doi.org/10.1046/j.1365-2664.2002.00743.x
Mevi-Schütz, J. \& Erhardt, A., 2003, 'Larval nutrition affects female nectar amino acid preference in the map butterfly (Arashnia levana)', Ecology 84(10), 2788-2794. https://doi.org/10.1890/02-3108

Moranz, R.A., Fuhlendorf, S.D. \& Engle, D.M., 2014, 'Making sense of a prairie butterfly paradox: The effects of grazing, time since fire, and sampling period on regal fritillary abundance', Biological Conservation 173(2014), 32-41. https://doi. org/10.1016/j.biocon.2014.03.003

Mucina, L. \& Rutherford, M.C., 2006, The vegetation of South Africa, Lesotho and Swaziland, South African National Biodiversity Institute, Pretoria.

New, T.R., Yen, A.L., Sands, D.P.A., Greenslade, P., Neville, P.J., York, A. et al., 2010, 'Planned fires and invertebrate conservation in south east Australia', Journal of Insect Conservation 14(5), 567-574. https://doi.org/10.1007/s10841-010-9284-4

Oksanen, J., Blanchet, F.G., Kindt, R., Legendre, P., Minchin, P.R., O'hara, R.B. et al., 2013, 'Package "vegan"', Community Ecology Package Version 2(9), 1-295.

Otto, H.H., 2014, Butterflies of the Kruger National Park \& surrounds, Herbert Otto, Barberton.

Parr, C.L. \& Andersen, A.N., 2006, 'Patch mosaic burning for biodiversity conservation: A critique of the pyrodiversity paradigm', Conservation Biology 20(6), 1610-1619. https://doi.org/10.1111/j.1523-1739.2006.00492.x

Parr, C.L. \& Chown, S.L., 2003, 'Burning issues for conservation: A critique of faunal fire research in Southern Africa', Austral Ecology 28(4), 384-395. https://doi. org/10.1046/j.1442-9993.2003.01296.x

Parr, C.L., Robertson, H.G., Biggs, H.C. \& Chown, S.L., 2004, 'Response of African savanna ants to long-term fire regimes', Journal of Applied Ecology 41(4), 630642. https://doi.org/10.1111/j.0021-8901.2004.00920.x

Pausas, J.G. \& Fernández-Muñoz, S., 2012, 'Fire regime changes in the Western Mediterranean Basin: From fuel-limited to drought-driven fire regime', Climatic Change 110(1), 215-226. https://doi.org/10.1007/s10584-011-0060-6

Pausas, J.G. \& Keeley, J.E., 2009, 'A burning story: The role of fire in the history of life', BioScience 59(7), 593-601. https://doi.org/10.1525/bio.2009.59.7.10

Pechony, O. \& Shindell, D.T., 2010, 'Driving forces of global wildfires over the past millennium and the forthcoming century', Proceedings of the National Academy of Sciences 107(45), 19167-19170. https://doi.org/10.1073/pnas. 1003669107

Pollard, E., 1977, 'A method for assessing changes in the abundance of butterflies', Biological Conservation 12(2), 115-134. https://doi.org/10.1016/0006-3207(77) 90065-9

Pollard, E. \& Yates, T.J., 1993, Monitoring butterflies for ecology and conservation, Chapman \& Hall, London.

Pryke, J.S. \& Samways, M.J., 2012, 'Differential resilience of invertebrates to fire', AustralEcology37(4),460-469.https://doi.org/10.1111/j.1442-9993.2011.02307.x

R Development Core Team, 2018, R: A language and environment for statistical computing, R Foundation for Statistical Computing, Vienna.

Robinson, N.M., Leonard, S.W.J., Ritchie, E.G., Bassett, M., Chia, E.K., Buckingham, S. et al., 2013, 'Refuges for fauna in fire-prone landscapes: Their ecological function and importance', Journal of Applied Ecology 50(6), 1321-1329. https://doi. org/10.1111/1365-2664.12153

Smit, I.P.J., Asner, G.P., Govender, N., Kennedy-Bowdoin, T., Knapp, D.E. \& Jacobson, J., 2010, 'Effects of fire on woody vegetation structure in African savanna', Ecological Applications 20(7), 1865-1875. https://doi.org/10.1890/09-0929.1

Smith, M.D., Wilgen, B.W., Van, Burns, C.E., Govender, N., Potgieter, A.L.F., Andelman, S. et al., 2012, 'Long-term effects of fire frequency and season on herbaceous vegetation in savannas of the Kruger National Park, South Africa', Journal of Plant Ecology 6(1), 71-83. https://doi.org/10.1093/jpe/rts014

Swengel, A.B., 2001, 'A literature review of insect responses to fire, compared to other conservation managements of open habitat', Biodiversity and Conservation 10(7), 1141-1169. https://doi.org/10.1023/A:1016683807033

Trollope, W., Van Wilgen, B., Trollope, L.A., Govender, N. \& Potgieter, A.L., 2014, 'The long-term effect of fire and grazing by wildlife on range condition in moist and arid savannas in the Kruger National Park', African Journal of Range \& Forage Science 31(3), 199-208. https://doi.org/10.2989/10220119.2014.884511

Van Wilgen, B.W., Biggs, H., O'Regan, S.P. \& Mare, N., 2000, 'Fire history of the savanna ecosystems in the Kruger National Park, South Africa, between 1941 and 1996', South African Journal of Science 96(4), 167-178.

Vasconcelos, S., Rodrigues, P., Palma, L., Mendes, L.F., Palminha, A., Catarino, L. et al., 2015, 'Through the eye of a butterfly: Assessing biodiversity impacts of cashew expansion in West Africa', Biological Conservation 191, 779-786. https://doi. org/10.1016/j.biocon.2015.08.032

Vogel, J.A., Koford, R.R. \& Debinski, D.M., 2010, 'Direct and indirect responses of tallgrass prairie butterflies to prescribed burning', Journal of Insect Conservation 14(6), 663-677. https://doi.org/10.1007/s10841-010-9295-1

Wilkerson, M.L., Roche, L.M. \& Young, T.P., 2013, 'Indirect effects of domestic and wild herbivores on butterflies in an African savanna', Ecology and Evolution 3(11) 3672-3682. https://doi.org/10.1002/ece3.744

Wood, P.A. \& Samways, M.J., 1991, 'Landscape element pattern and continuity of butterfly flight paths in an ecologically landscaped botanic garden, Natal, South Africa', Biological Conservation 58(2), 149-166. https://doi.org/10.1016/00063207(91)90117-R

Woodhall, S., 2005, Field guide to butterflies of South Africa, Struik, Cape Town. 